
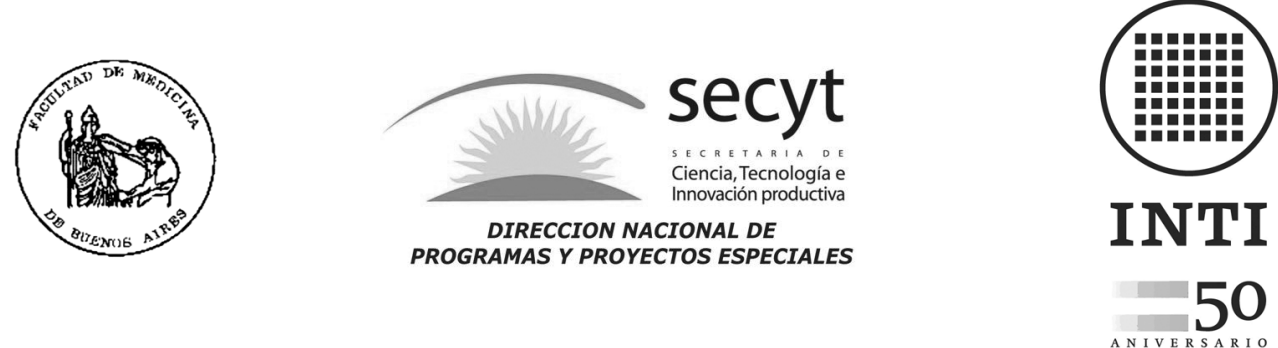

\title{
Red Nacional de Laboratorios Públicos Productores de Medicamentos
}

El día 13 de septiembre de 2007 a las 17:00 Hs., se llevó a cabo en el Salón del Decanato de la Facultad de Medicina de la UBA, sito en Paraguay $21551^{\circ}$ Piso de la Ciudad Autónoma de Buenos Aires, la firma del Acta de Constitución de la Red Nacional de Laboratorios Públicos de Producción de Medicamentos.

Este evento, organizado por el Programa Especial de Salud de la Dirección Nacional de Programas y Proyectos Especiales (DNPyPE) de la SeCyT, junto a la Cátedra Libre de Salud y Derechos Humanos de la Facultad de Medicina de la UBA y el Instituto Nacional de Tecnología Industrial, reviste una trascendencia particular, ya que constituye un paso significativo en la articulación de los laboratorios estatales de medicamentos y su articulación con el sistema científico y tecnológico.

La RED tendrá por objeto unir voluntades para llevar a cabo articulaciones entre los convocantes a los fines de estimular la producción estatal de medicamentos, así como propender la investigación y el desarrollo de nuevos productos, formulaciones, aplicaciones, métodos y todo aquello relacionado al campo de los medicamentos y su implicancia con la mejora de la salud de la población, con la correspondiente relevancia y pertinencia social para el país. Todas las acciones que se desarrollen dentro de la RED serán adoptadas de común acuerdo o por acuerdo de partes y se llevarán a cabo utilizando los instrumentos que ellas consideren más apropiados.

Avanzar en esta integración permitirá, entre otras cosas:

$\rightarrow$ Realizar compras conjuntas de insumos y, eventualmente, de equipamiento, abaratando significativamente los costos.

$\rightarrow$ Intercambiar productos entre laboratorios, disminuyendo la cantidad de diferentes específicos producidos por cada uno y aumentando su volumen. Esto, además de reducir costos y optimizar la utilización de las plantas, mejora y facilita sustancialmente los registros ante la ANMAT.

$\rightarrow$ Intercambiar servicios.

$\rightarrow$ Obtener todos los laboratorios las certificaciones y habilitaciones de la autoridad regulatoria nacional.

$\rightarrow$ Entablar en conjunto acciones para obtener financiamiento para inversiones.

$\rightarrow$ Articular estrategias hacia el interior y el exterior del país.

$\rightarrow$ Avanzar en la integración del sector de producción con el sector científico/tecnológico (Universidades, Centros e Institutos de I+D) 